Florentinus, S.R., Hulten, R. van, Kloth, M.E.M., Heerdink, E.R., Griens, A.M.G.F., Leufkens, H.G.M., Groenewegen, P.P. The effect of pharmacotherapy audit meetings on early new drug prescribing by general practitioners. Annals of Pharmacotherapy: 2007, 41(2), 319-324

\begin{tabular}{|c|c|}
\hline Postprint Version & 1.0 \\
\hline Journal website & http://www.theannals.com/cgi/content/full/41/2/319 \\
\hline Pubmed link & $\begin{array}{l}\text { http://www.ncbi.nlm.nih.gov/pubmed/17244644?ordinalpos=1\&itool=EntrezSy } \\
\text { stem2.PEntrez.Pubmed.Pubmed_ResultsPanel.Pubmed_RVDocSum }\end{array}$ \\
\hline DOI & $\overline{10.1345 / \mathrm{aph} .1 \mathrm{H} 250}$ \\
\hline
\end{tabular}

This is a NIVEL certified Post Print, more info at http://www.nivel.eu

\title{
The Effect of Pharmacotherapy Audit Meetings on Early New Drug Prescribing by General Practitioners
}

\author{
STEFAN R FLORENTINUS, ROLF VAN HULTEN, MARJOLEIN EM KLOTH, EIBERT R \\ HEERdinK, AMG FABIËNNE GRIENS, Hubert GM LEUfKENS, AND PETER P GROENEWEGEN
}

\begin{abstract}
BACKGROUND: New drugs are cornerstones of clinical practice. However, when included in practice in an erratic fashion, there is valid concern about uncertain risk-benefit for patients and increased healthcare expenditures. In several countries, general practitioners (GPs) and pharmacists work closely together to ensure proper use of new drugs in clinical practice.
\end{abstract}

OBJECTIVE: To estimate the effect of pharmacotherapy audit meetings (PTAMs) between GPs and community pharmacists on prescribing of newly marketed drugs by GPs.

METHODS: We conducted an observational study of new drug prescribing in a cohort of 103 GPs, working in 59 practices, from 1999 until 2003. The main outcome measures were the decisions to start therapy with a new drug or with an existing older drug from the same therapeutic category within the first 6 months after market introduction. Multilevel modeling was used for analyses.

RESULTS: Overall, in $6.1 \%$ of the decisions to start drug therapy, GPs chose the drug that was most recently introduced into the market. The GPs attending low-quality PTAMs made 1861 decisions to start therapy; in 112 (6.0\%) of those decisions, a new drug was preferred over an older alternative. GPs participating in high-quality PTAMs preferred a new drug in only $3.4 \%$ of the 3138 decisions made. Compared with GPs participating in PTAMs on the highest quality level (level 4), GPS attending level 1 or level 2 PTAMs were more than twice as likely to start therapy with new drugs than with older drugs (OR 2.24; 95\% CI 1.04 to 4.81 vs OR 2.31 ; $95 \%$ CI 1.30 to 4.09 , respectively).

CONCLUSIONS: PTAMs may be an effective way to control early prescribing of new drugs in general practice. For PTAMs to be effective, it is vital that GPs and pharmacists set common goals on how to optimize pharmacotherapy. This concordance should be reflected in PTAMs that result in concrete decisions with 
Florentinus, S.R., Hulten, R. van, Kloth, M.E.M., Heerdink, E.R., Griens, A.M.G.F., Leufkens, H.G.M., Groenewegen, P.P. The effect of pharmacotherapy audit meetings on early new drug prescribing by general practitioners. Annals of Pharmacotherapy: 2007, 41(2), 319-324

auditing of GP prescribing behavior. Pharmacists should play an active role in organizing PTAMs to increase their influence on drug prescribing.

Innovation in pharmacotherapy is a cornerstone in clinical practice. However, prescribing of newly marketed drugs is not uniformly distributed among physicians, and some new drugs are prescribed more than medical need can account for. ${ }^{1-3}$ Erratic inclusion of new drugs into clinical practice fuels the ongoing discussion about the trade-off between the wish to treat patients more effectively and ensuring sustainable cost-containment in health care. ${ }^{4-6}$ With an aging population and an increasing ability to treat many chronic diseases with medicines, general practitioners (GPs) report difficulties in staying up-to-date with medical innovations. ${ }^{7-9}$ To ensure that optimal care is given to patients, a teamwork approach by healthcare professionals is important. ${ }^{10,11}$

In the Netherlands, community pharmacists and GPs practicing in the same catchment area regularly organize pharmacotherapy audit meetings (PTAMs) to improve the quality of prescribing by making decisions on first choice treatment. ${ }^{12,13}$ PTAMs are defined as a series of regular meetings between GPs and pharmacists during which information and views about pharmacotherapy are exchanged with the aim to improve the prescribing and dispensing of drugs. ${ }^{13}$ Participation in PTAMs is voluntary for pharmacists and GPs, and the participants decide which topics are discussed during the meetings. Clinical assessment of newly marketed drugs is one important topic on the agenda in more than $70 \%$ of all PTAMs. ${ }^{13,14}$ In 2003, 794 PTAMs, consisting on average of 9 GPs and 2 pharmacists, were active. These numbers indicate that nearly all Dutch GPs and community pharmacists participate in PTAMs.

The literature pertaining to the effect of PTAMs on GP prescribing behavior is limited and, in addition, does not address their effect on new drug prescribing. ${ }^{13,15}$ Therefore, the purpose of the present study was to estimate the effect of PTAMs on prescribing of newly marketed drugs by GPs.

\section{METHODS}

\section{Setting}

This study used dispensing data from patients of 103 GPs who participated in the second Dutch national survey of general practice (DNSGP-2), conducted by the Netherlands Institute for Health Services Research in 2001. ${ }^{16}$ All GPs who participated in the DNSGP-2 listed the pharmacies where most of their patients filled their prescriptions. These pharmacies were invited to participate in the study by letter and, if necessary, followed up with a telephone call 1-2 weeks later. From the pharmacies that agreed to participate, dispensing data of the GPs were collected from the SFK (Foundation for Pharmaceutical Statistics). ${ }^{17}$ The 103 GPs worked in 59 nondispensing practices in all 12 provinces of the Netherlands. Dispensing data covered the years 1999 until 2003. Information on the selection of GPs and pharmacies and subsequent linking of the GP data to the pharmacy dispensing data is presented in detail elsewhere. ${ }^{18}$ Because virtually all patients in the Netherlands designate a single pharmacy to fill prescriptions from GPs and medical specialists, dispensing data provide an almost complete account of drug exposure over time. ${ }^{19}$ The 103 GPs worked in 59 nondispensing practices in all 12 provinces of the Netherlands. The characteristics of the GPs were comparable with those of the original sample of the DNSGP-2 with respect to type of office, location of those in deprived areas, and degree of urbanization. ${ }^{18}$

Data on PTAMs were collected through a questionnaire sent in December 2003 to 123 community pharmacies that worked closely together with the 103 GPs. The pharmacist most actively involved in the PTAMs filled in the questionnaire, which requested information on the quality, composition, and content of the PTAMs. In the Netherlands, PTAMs are categorized into 4 levels based on their capability to make decisions as follows ${ }^{13}$ : level $1=$ 
Florentinus, S.R., Hulten, R. van, Kloth, M.E.M., Heerdink, E.R., Griens, A.M.G.F., Leufkens, H.G.M., Groenewegen, P.P. The effect of pharmacotherapy audit meetings on early new drug prescribing by general practitioners. Annals of Pharmacotherapy: 2007, 41(2), 319-324

no structured meetings, level 2 = frequent meetings without concrete decisions, level 3 = frequent meetings with concrete decisions, and level 4 = frequent meetings with concrete decisions and evaluation of these decisions. The differences between the different levels are mainly the ability to make decisions and to evaluate these decisions in subsequent meetings. PTAMs do not have a legal basis, but merely consist of professional commitment of the participants to make decisions. If more than one pharmacist attended the same PTAM and their assessment of the PTAM's quality differed, the lowest value was used in the analysis to avoid overestimation of the effectiveness of the PTAMs.

In this setting, 5 new drugs were selected as study cases: (1) the combination of the longacting bronchodilator salmeterol and inhaled corticosteroid fluticasone, (2) the cyclooxygenase-2 inhibitor rofecoxib, (3) the proton pump inhibitor esomeprazole, (4) the long-acting anticholinergic bronchodilator tiotropium, and (5) the statin rosuvastatin. Table 1 shows some relevant characteristics of these case study drugs. All 5 new drugs showed rapid market penetration and were listed within one year after market introduction in the top 10 drugs associated with the fastest growing expenditures in the Netherlands. ${ }^{17}$ As reference drugs for the selected case study drugs, we used, respectively, (1) all long-acting $\beta^{2}$ antagonists and inhaled corticosteroids, (2) all nonsteroidal antiinflammatory drugs, except low-dose aspirin, (3) all proton pump inhibitors, (4) all ipratropium bromide-containing products, and (5) all statins.

\section{[TABLE 1]}

\section{Design}

With the introduction of a new drug, GPs can choose to treat a patient with either the older one that has proven effectiveness (if available) or the newly introduced agent. For this study, we included all patients receiving a new or an older reference drug during the first 6 months after the market introduction. The primary outcome measure was the GP's decision to start drug therapy in patients with a new or reference drug. The date of the patient's first prescription for either drug was termed the index date. Starting was defined as receiving a prescription for a new or reference drug and no prescription for the same drug the 6 months before the index date. Patients who had no refills within 6 months after the initial prescription were excluded. Both new starters and switchers were included in the analysis.

\section{Data Analysis}

To estimate the effect of PTAMs on new drug prescribing, we used a logistic multilevel model with 2 levels, namely, patients nested within GPs. For practical reasons, we eliminated the practice or the pharmacy where the GPs' patients usually go to as a level; a 3-level model would have been very difficult to create. Characteristics of PTAMs were modeled as characteristics of GPs. Using a multilevel model enabled us to adjust for differences between patients and clustering of patients within GPs that might affect a GP's decision to prescribe new drugs. ${ }^{20}$ Instead of running separate analyses for the 5 different new drug and reference drug groups, we included dummies to represent the groups. In this way, we took into account that new drug prescribing in one group might be related to that in other groups. The patient's age, gender, and chronic disease score ${ }^{21}$ were used to adjust for any patient influences. Odds ratios with 95\% confidence intervals were estimated for all PTAM characteristics one by one and adjusted for all patient characteristics. Due to the relatively small number of GPs, we were unable to perform a multivariate multilevel analysis to adjust for all characteristics simultaneously.

\section{RESULTS}

For 86 (83.5\%) of the 103 GPs, both dispensing data and information on PTAMs were available. The average age was 46.6 years $(S D=6.3), 26.7 \%$ were female, and $53.5 \%$ worked alone. The GPs on which no information on PTAMs was available did not differ 
Florentinus, S.R., Hulten, R. van, Kloth, M.E.M., Heerdink, E.R., Griens, A.M.G.F., Leufkens, H.G.M., Groenewegen, P.P. The effect of pharmacotherapy audit meetings on early new drug prescribing by general practitioners. Annals of Pharmacotherapy: 2007, 41(2), 319-324

from the other GPs with respect to age and gender. The proportion of GPs prescribing the new drugs during the first 6 months after market introduction ranged from $31.6 \%$ for esomeprazole to $74.0 \%$ for tiotropium. Rofecoxib was prescribed by $69.0 \%$, rosuvastatin by $43.2 \%$, and salmeterol/fluticasone by $43.3 \%$ of the population.

In total, 849 patients were identified as having been started on 1 of the 5 new drugs and 13 149 patients as starters on 1 of the older reference drugs (Table 2). This means that, in $6.1 \%$ of the decisions to initiate therapy, the drug most recently marketed was prescribed. The number of patients starting on a newly marketed drug was highest for tiotropium (29.5\%) and lowest for salmeterol/fluticasone (2.2\%). Of all patients starting rofecoxib, 56.4\% were switchers. For rosuvastatin, 55.9\% were switchers; for tiotropium, 37.6\%; for esomeprazole, 49\%; and for salmeterol/fluticasone, 56.4\%.

\section{[TABLE 2]}

As shown in Table 2, the preference for the latest drug on the market increased when GPs participated in low-quality PTAMs. Out of the 1861 decisions to initiate new therapy, in 112 (6.0\%) cases a new drug was chosen over an older alternative by the GPs attending lowquality PTAMs. The decision to prescribe a newly marketed drug was made in 108 of the total of 3138 (3.4\%) times that therapy was started by the GPs attending high-quality level 4 PTAMs.

The findings shown in Table 2 were confirmed by multilevel analysis. When adjusted for the patients' age, gender, and chronic disease score, the GPs attending level 1 PTAMs (OR = 2.24; $95 \%$ CI 1.04 to 4.81 ) or level 2 PTAMs (OR $=2.31$; 95\% CI 1.30 to 4.09 ) were more than twice as likely to prescribe drugs in the early postmarketing period than GPs participating in PTAMs on the highest level (level 4) (Table 3).

\section{[TABLE 3]}

In addition, we noted that, as the number of GPs attending the PTAMs increased, GPs prescribed new drugs more frequently ( $\mathrm{OR}=1.05$; 95\% CI 1.01 to 1.09$)$ (Table 3). The same trend was observed for the total number of PTAM participants (OR $=1.06$; 95\% CI 1.02 to 1.10). GPs participating in PTAMs that made decisions about who receives pharmaceutical representatives were less likely to prescribe new drugs ( $\mathrm{OR}=0.36$; $95 \%$ CI 0.24 to 0.56 ).

\section{DISCUSSION}

The objective of this study was to evaluate the effect of PTAMs on new drug prescribing by GPs during the first 6 months following market introduction. Our findings show that early new drug prescribing by GPs is restricted when the physicians and community pharmacists collaborate in high-quality PTAMs that make concrete decisions to optimize pharmacotherapy and evaluate GPs' prescribing behavior.

The main strength of our study is that we analyzed new drug prescribing by GPs in a multilevel structure of patients clustered in GPs, while also taking into account the physicians' professional interactions with community pharmacists. We noted that GPs participating in low-quality PTAMs, namely those that do not have frequent meetings and fail to make decisions to optimize pharmacotherapy, prescribe more new drugs compared with GPs participating in high-quality PTAMs. There may be several explanations for this finding. One explanation, of course, is a direct effect of PTAMs on a GP's decision to prescribe a new drug. Making decisions to optimize pharmacotherapy may result in a restriction on the number of drugs GPs can prescribe, especially when their prescribing behavior is evaluated.

Another explanation may be the participants' attitudes toward new drugs. GPs who are willing to professionalize PTAMs to function on level 4 may have different attitudes regarding new drug prescribing than those attending non-committal PTAMs. Prosser and Walley 22 noted that new drug prescribing depends on a GP's beliefs rather than objective 
Florentinus, S.R., Hulten, R. van, Kloth, M.E.M., Heerdink, E.R., Griens, A.M.G.F., Leufkens, H.G.M., Groenewegen, P.P. The effect of pharmacotherapy audit meetings on early new drug prescribing by general practitioners. Annals of Pharmacotherapy: 2007, 41(2), 319-324

evaluation of the literature. Those with a negative attitude toward prescribing of new drugs might also influence and support the decisions of other prescribers. ${ }^{23}$ In addition, GPs participating in the same PTAMs show more resemblance in their prescribing behavior compared with GPs participating in different PTAMs. ${ }^{13}$ Therefore, further research is needed to elucidate whether the GPs' restraint in new drug prescribing is the result of decisions made during PTAMs.

Some conditions need to be met before PTAMs are effective in influencing GP prescribing behavior. A key prerequisite for PTAMs to reach decisions about optimizing pharmacotherapy is a group of willing GPs and pharmacists. We found that only GPs participating in PTAMs with a sufficient internal basis to make decisions prescribed fewer new drugs. In addition, physicians participating in smaller PTAMs prescribed fewer new drugs. As the number of participants per PTAM increases, effectiveness seems to decrease and GPs prescribe more new drugs. Veninga et al. ${ }^{24}$ recommended that the optimal number of participants for PTAMs is 5-6 healthcare practitioners and that participants in smaller groups were shown to be more satisfied with the climate in the group.

Our data show that PTAMs that made decisions about who receives visits from pharmaceutical representatives had a limiting effect on new drug prescribing. Moreover, our results may indicate that inviting pharmaceutical representatives to PTAMs resulted in more new drug prescribing. Numerous studies have shown that receiving visits from

pharmaceutical representatives is a strong predictor for adopting new drugs. ${ }^{25,26}$ The wish to stay up to date with medical advances is often mentioned by physicians as a reason for seeing pharmaceutical representatives. ${ }^{7,22}$ In our study, some GPs who participated in level 4 PTAMs decided not to see pharmaceutical representatives themselves, but instead agreed that only pharmacists received visits. The information on a new drug can be filtered and assessed as to its scientific value by pharmacists and subsequently discussed during PTAMs. This might offer a valuable opportunity for GPs to save time and stay up to date, with limited commercial influences.

The results of our study need to be interpreted in light of its limitations. Our results are based on the prescribing of 5 new drugs; therefore, generalizing these results to all new drugs should be done with restraint. However, the case drugs used here are clear examples of rapid market uptake with a strong rise in healthcare expenditures. The main limitation of our study is that, due to the relatively low number of physicians, we were unable to estimate the effect of PTAMs in a multivariate model. Furthermore, characteristics of PTAMs were collected through a questionnaire completed only by pharmacists, and the most conservative assessments were used in the analysis. Other studies have identified differences between GPs' and pharmacists' perceptions regarding the quality of PTAMs. ${ }^{13,27}$ In general, physicians rate the quality of PTAMs higher than the rating given by pharmacists.

\section{CONCLUSIONS}

Professional collaboration between GPs and community pharmacists in PTAMs is an effective way to control early new drug prescribing in general practice. For PTAMs to be effective, it is vital that GPs and pharmacists set common goals on how to optimize pharmacotherapy. This concordance should be reflected in PTAMs with frequent meetings that result in concrete decisions with auditing of GP prescribing behavior. Pharmacists should play an active role in organizing PTAMs to increase their influence on prescribing.

\section{REFERENCES}

Inman W, Pearce G. Prescriber profile and post-marketing surveillance. Lancet 1993;342:658-61.

Tamblyn R, McLeod P, Hanley JA, Girard N, Hurley J. Physician and practice characteristics associated with the early utilization of new prescription drugs. Med Care 2003;41:895-908. 
Florentinus, S.R., Hulten, R. van, Kloth, M.E.M., Heerdink, E.R., Griens, A.M.G.F., Leufkens, H.G.M., Groenewegen, P.P. The effect of pharmacotherapy audit meetings on early new drug prescribing by general practitioners. Annals of Pharmacotherapy: 2007, 41(2), 319-324

Dybdahl T, Andersen M, Sondergaard J, Kragstrup J, Kristiansen IS. Does the early adopter of drugs exist? A population-based study of general practitioners' prescribing of new drugs. Eur J Clin Pharmacol 2004;60:667-2.

Friedman MA, Woodcock J, Lumpkin MM, Shuren JE, Hass AE, Thompson LJ. The safety of newly approved medicines: do recent market removals mean there is a problem? JAMA 1999;281:1728-34.

Florentinus SR, Heerdink ER, Klungel OH, de Boer A. Should rosuvastatin be withdrawn from the market (letter)? Lancet 2004;364: 1577; author reply 1578-9

Florentinus S, Heerdink ER, de Boer A, van Dijk L, Leufkens HGM. The trade-off between cardiovascular and gastrointestinal effects of rofecoxib. Pharmacoepidemiol Drug Saf 2005;14:437-41.

Jones MI, Greenfield M, Bradley CP. Prescribing new drugs: qualitative study of influences on consultants and general practitioners. BMJ 2001;323:378-85.

Jacoby A, Smith M, Eccles M. A qualitative study to explore influences on general practitioners' decisions to prescribe new drugs. Br J Gen Pract 2003;53:120-5.

Prosser H, Almond S, Walley T. Influences on GPs' decision to prescribe new drugs-the importance of who says what. Fam Pract 2003;20:61-8.

Zillich AJ, McDonough RP, Carter BL, Doucette WR. Influential characteristics of physician/pharmacist collaborative relationships. Ann Pharmacother 2004;38:764-70 DOI10.1345/aph.1D419

Hughes CM, McCann S. Perceived interprofessional barriers between community pharmacists and general practitioners: a qualitative assessment. Br J Gen Pract 2003;53:600-6.

Blom AT, Paes AH, Bakker A, Koopman CJ, van der Meer C. Pharmacist-physician cooperation at a regional level. Pharm World Sci 1994; 16:13-7

Van Dijk L, Barnhoorn H, De Bakker DH. [Pharmacotherapy audit meetings in 1999: the state of affairs] Dutch. Utrecht: NIVEL, 2001.

DGV. FTO-peiling 2003 [Dutch]. Utrecht. Dutch Institute for Effective Use of Medication, 2003. www.medicijngebruik.nl/content/17_vind_op_thema/17-7-1.htm (accessed 2005 Aug 10).

Muijrers PEM, Grol RPTM, Sijbrandij J, Janknegt R, Knottnerus JA. Differences in prescribing between GPs. Impact of the cooperation with pharmacists and impact of visits from pharmaceutical industry representatives. Fam Pract 2005;22:624-30.

Westert GP, Schellevis FG, de Bakker DH, Groenewegen PP, Bensing JM, van der Zee J. Monitoring health inequalities through general practice: the Second Dutch National Survey of General Practice. Eur J Public Health 2005;15:59-65.

Tinke J, Griens A. Facts and figures 2003. The Hague, Netherlands. http://www.sfk.nl/, Foundation for Pharmaceutical Statistics, 2003.

Florentinus SR, Souverein PC, Griens FA, Groenewegen PP, Leufkens HG, Heerdink ER. Linking community pharmacy dispensing data to prescribing data of general practitioners. BMC Med Inform Decis Mak 2006;6: 18. DOI10.1186/1472-6947-6-18

Herings RMC, Bakker A, Stricker BH, Nap G. Pharmaco-morbidity linkage: a feasibility study comparing morbidity in two pharmacy based exposure cohorts. J Epidemiol Commun Health 1992;46:136-40.

Leyland $\mathrm{AH}$, Groenewegen PP. Multilevel modelling and public health policy. Scand J Public Health 2003;31:267-74.

Von Korff M, Wagner EH, Saunders K. A chronic disease score from automated pharmacy data. J Clin Epidemiol 1992;45:197-203.

Prosser H, Walley $\mathrm{T}$. New drug uptake: qualitative comparison of high and low prescribing GPs' attitudes and approach. Fam Pract 2003; 20:583-91.

De Jong JD, Groenewegen PP, Westert GP. Mutual influences of general practitioners in partnerships. Soc Sci Med 2003;57:1515-24.

Veninga CCM, Denig P, Zwaagstra R, Haaijer-Ruskamp FM. Improving drug treatment in general practice. J Clin Epidemiol 2000;53:762-72.

Blumenthal D. Doctors and drug companies. N Engl J Med 2004;351:1885-90.

Watkins C, Moore L, Harvey I, Carthy P, Robinson E, Brawn R. Characteristics of general practitioners who frequently see drug industry representatives: national cross sectional study. BMJ 2003;326:1178-9. 
Florentinus, S.R., Hulten, R. van, Kloth, M.E.M., Heerdink, E.R., Griens, A.M.G.F., Leufkens, H.G.M., Groenewegen, P.P. The effect of pharmacotherapy audit meetings on early new drug prescribing by general practitioners. Annals of Pharmacotherapy: 2007, 41(2), 319-324

Muijrers PE, Knottnerus JA, Sijbrandij J, Janknegt R, Grol RP. Changing relationships: attitudes and opinions of general practitioners and pharmacists regarding the role of the community pharmacist. Pharm World Sci 2003;25:235-41.

\section{TABLES}

\begin{tabular}{|c|c|c|c|}
\hline Rofecoxib $^{b}$ & April 2000 & rheumatoid arthritis & NSAIDs, excluding low-dose aspirin \\
\hline Esomeprazole & November 2000 & GERD & PPIs \\
\hline Tiotropium & June 2002 & COPD & ipratropium bromide-containing products \\
\hline
\end{tabular}

\begin{tabular}{|c|c|c|c|c|c|c|c|}
\hline $\begin{array}{l}\text { PTAM } \\
\text { Level }^{\mathrm{a}}\end{array}$ & GPs, n (\%) & $\begin{array}{c}\text { Esomeprazole, } \\
n(\%)\end{array}$ & $\begin{array}{c}\text { Rofecoxib, } \\
\text { n (\%) }\end{array}$ & $\begin{array}{c}\text { Rosuvastatin, } \\
\mathrm{n}(\%)\end{array}$ & $\begin{array}{c}\text { Salmeterol/ } \\
\text { Fluticasone, } \\
\mathrm{n}(\%)\end{array}$ & $\begin{array}{c}\text { Tiotropium, } \\
\text { n (\%) }\end{array}$ & $\begin{array}{c}\text { Overall, } \\
\text { n (\%) }\end{array}$ \\
\hline 4 & $25(29.1)$ & 14/358 (3.9) & $36 / 2092(1.7)$ & $10 / 148(6.8)$ & 4/394 (1.0) & 44/146 (30.1) & $108 / 3138(3.4)$ \\
\hline 3 & $17(19.8)$ & $19 / 336(5.7)$ & $110 / 2186(5.0)$ & $35 / 134(26.1)$ & $7 / 617$ (1.1) & $73 / 241$ (30.3) & $244 / 3514(6.9)$ \\
\hline 2 & $35(40.7)$ & $39 / 671(5.8)$ & $161 / 3222(5.0)$ & $50 / 218(22.9)$ & $37 / 1005$ (3.7) & $98 / 368(26.6)$ & $385 / 5484(7.0)$ \\
\hline 1 & $9(10.5)$ & $12 / 142(8.5)$ & $46 / 1129(4.1)$ & 14/67 (20.9) & 6/433 (1.4) & $34 / 90$ (37.8) & $112 / 1861(6.0)$ \\
\hline TOTAL & $86(100)$ & $84 / 1507(5.6)$ & $353 / 8629(4.1)$ & $109 / 567(19.2)$ & $54 / 2449(2.2)$ & $249 / 845$ (29.5) & $849 / 13997(6.1)$ \\
\hline
\end{tabular}




\begin{tabular}{|c|c|c|}
\hline \multicolumn{3}{|c|}{$\begin{array}{l}\text { Table 3. Multilevel Regression Analysis of } \\
\text { New Drug Prescribinga }\end{array}$} \\
\hline \multicolumn{3}{|c|}{ Basic model including drugs and pt. characteristics } \\
\hline New drug $\quad \mathrm{C}$ & \multicolumn{2}{|c|}{ Coefficient, \% $(95 \% \mathrm{Cl})$} \\
\hline esomeprazole & \multicolumn{2}{|c|}{$1.5(1.0$ to 2.5$)$} \\
\hline rofecoxib & \multicolumn{2}{|c|}{1.9 (1.3 to 2.6$)$} \\
\hline rosuvastatin & \multicolumn{2}{|c|}{$6.3(4.0$ to 10.0$)$} \\
\hline salmeterol/fluticasone & \multicolumn{2}{|c|}{$1.6(1.1$ to 2.4$)$} \\
\hline tiotropium & \multicolumn{2}{|c|}{$17.0(12.0$ to 24.0$)$} \\
\hline \multicolumn{2}{|l|}{ Pt. characteristics } & \\
\hline female, $\mathrm{n}(\%)$ & \multicolumn{2}{|l|}{9706 (58.5) } \\
\hline age, mean $\pm S D$ & $50.2 \pm 20.2$ & $1.02(1.02$ to 1.02$)$ \\
\hline $\begin{array}{l}\text { chronic disease score, } \\
\text { mean } \pm \text { SD }\end{array}$ & $2.32 \pm 2.7$ & $1.06(1.04$ to 1.09$)$ \\
\hline \multicolumn{3}{|c|}{ Basic model plus PTAM characteristics, introduced one at a time } \\
\hline Quality level of PTAMs ${ }^{b}$ & $\begin{array}{r}\text { haracteristics, } \\
\text { GPs, } \mathrm{n}(\%)\end{array}$ & OR $(95 \% \mathrm{Cl})$ \\
\hline level 4 & $25(28.1)$ & reference \\
\hline level 3 & $17(19.1)$ & $1.49(0.77$ to 2.88$)$ \\
\hline level 2 & $35(39.3)$ & $2.31(1.30$ to 4.09$)$ \\
\hline level 1 & $9(10.1)$ & $2.24(1.04$ to 4.81$)$ \\
\hline \multicolumn{3}{|c|}{ Composition of PTAMs, mean \pm SD } \\
\hline pharmacists, $\mathrm{n}$ & $3.5 \pm 2.0$ & $1.06(0.97$ to 1.16$)$ \\
\hline pharmacies, $\mathrm{n}$ & $2.2 \pm 1.0$ & 1.05 (0.98 to 1.12$)$ \\
\hline GPs, $n$ & $9.5 \pm$ & 1 to 1.09 ) \\
\hline total participants & $13.0 \pm 5.3$ & $1.06(1.02$ to 1.10$)$ \\
\hline Other PTAM characteristics & s $\quad$ GPs, $n(\%)$ & OR $(95 \% \mathrm{Cl})$ \\
\hline \multicolumn{3}{|c|}{ Are newly marketed drugs discussed during PTAMs? } \\
\hline yes & $82(92.1)$ & $0.59(0.12$ to 2.87$)$ \\
\hline \multicolumn{3}{|c|}{$\begin{array}{l}\text { Are decisions about which new drugs should or should not be } \\
\text { prescribed made during PTAMs? }\end{array}$} \\
\hline yes & $27(30.3)$ & $0.82(0.50$ to 1.33$)$ \\
\hline \multicolumn{3}{|c|}{$\begin{array}{l}\text { Are decisions about which drugs are first choice made during } \\
\text { PTAMs? }\end{array}$} \\
\hline yes & $68(76.4)$ & $0.88(0.50$ to 1.54$)$ \\
\hline \multicolumn{3}{|c|}{ Are pharmaceutical representatives invited to attend PTAMs? } \\
\hline yes & $11(12.4)$ & $1.54(0.81$ to 2.96$)$ \\
\hline \multicolumn{3}{|c|}{$\begin{array}{l}\text { Are decisions about who receives pharmaceutical representatives } \\
\text { made during PTAMs? }\end{array}$} \\
\hline yes & $41(46.1)$ & $0.36(0.24$ to 0.56$)$ \\
\hline \multicolumn{3}{|c|}{$\begin{array}{l}\text { GP = general practitioner; PTAM = pharmacotherapy audit meeting. } \\
\text { aSignificant findings in bold type. } \\
\text { bLevel } 4 \text { = frequent meetings with concrete decisions and evaluation of } \\
\text { these decisions (highest quality); level } 3=\text { frequent meetings with } \\
\text { concrete decisions; level } 2 \text { = frequent meetings without concrete de- } \\
\text { cisions; level } 1=\text { no structured meetings (lowest quality). }\end{array}$} \\
\hline
\end{tabular}

